\title{
Laparoscopic Inguinal Hernia Repair and Mesh Infection: Does the Type of Mesh Used Matter?
}

Nigel Bascombe*, Chrystal Calderon, Otis Payne, Kelly-Ann Bobb, Dave Harnanan and Dilip Dan

Department of Clinical Surgical Sciences, University of the West Indies (UWI), Eric Williams Medical Sciences Complex (EWMSC), Champ Fleur, Trinidad and Tobago

*Correcsponding author: Nigel Bascombe, Department of Clinical Surgical Sciences, UWI, 2nd floor, Building 68, EWMSC, Champ Fleur, Trinidad and Tobago, Tel: 1-868-683-7858; Fax: 1-868-632-9168; E-mail: nigelantonio@hotmail.com

Received date: January 21, 2017; Accepted date: January 29, 2017; Published date: February 28, 2017

Copyright: $\odot 2017$ Bascombe N. This is an open-access article distributed under the terms of the Creative Commons Attribution License, which permits unrestricted use, distribution, and reproduction in any medium, provided the original author and source are credited.

\begin{abstract}
Objective: Mesh infection post laparoscopic inguinal hernia repair is an uncommon complication. This increases patient morbidity and overall cost of a relatively low risk procedure. In this article, we sought to highlight the possible relationship between mesh infection and the biological nature of the mesh.
\end{abstract}

Methods: Data of laparoscopic inguinal hernia repair was collected retrospectively from two separate private institutions, which were performed over a 5-year period. All information collected, including type of mesh used and arising complications, were documented on a computerized database.

Results: Over the period of January 2011 and December 2015, a total of 81 elective laparoscopic inguinal hernia repairs were performed-59 from institution $A$ and 22 from institution $B$. All repairs were performed by the same surgeon, using the Trans abdominal pre-peritoneal (TAPP) approach. Twelve repairs demonstrated evidence of mesh infection during this time frame, six (6) from each institution. Of these 12 cases, all underwent laparoscopic removal of the infected mesh, except one. All removed mesh was made of a polyester material.

Conclusion: The associated advantages of using mesh to repair inguinal hernias are numerous and it is a great asset in modern day surgery. The choice of the "right" mesh to use should depend on surgeon experience, personal outcome and of course, evidence-based.

Keywords: Mesh; Infection; Laparoscopic inguinal hernia repair

\section{Introduction}

It was Ger in 1982 who first described minimal access surgery for laparoscopic inguinal hernia repairs [1]. Over the last two decades, laparoscopic repair has become one of the accepted standards of inguinal herniorrhaphy, notably the Trans abdominal pre-peritoneal repair (TAPP) and the total extra- peritoneal repair (TEP) [2]. In the Anglophone Caribbean, strides and leaps are being taken in this field3. In addition to challenges in initiating and establishing these operative procedures in tertiary health institutions, there is the further burden of managing possible complications that may arise.

Mesh infection is very uncommon post laparoscopic inguinal hernia repair-with rates of infection being noted as low as $0 \%$ in Caribbean literature. However, some authors have described rates as high as $0.5 \%$ $-1 \%$ in other literature, and, despite the varied incidence of mesh infection-it is clear, that it is certainly not the common phenomena $[3,4]$.

Mesh infection can be categorised as either early or late/delayed onset mesh infection. Early mesh infection occurring more commonly, usually presenting within days or weeks post operation. At least fifty percent $(50 \%)$ of cases are expected to occur within the first month post operation [5]. Several factors have been researched, in an attempt to find a likely causative factor. One of those recurrently highlighted, is not only the type of mesh used, but also its inherent biological properties. Understanding the different structural components of the plethora of mesh available, may give the surgeon better clarity when choosing his best option.

\section{Method}

Data was collected retrospectively from the operative logbooks of two separate private institutions during the period of 2011 and 2015. All elective laparoscopic inguinal hernia repairs and any cases of mesh removal after laparoscopic inguinal herniorrhaphy were recorded in an electronic database. These were then used to attain the patients file records.

Some of the patients, who had undergone removal of infected mesh during the above time frame, were contacted via telephone and a brief interview of current clinical status was conducted.

\section{Results}

The elective laparoscopic inguinal hernia repairs performed at two private institutions were collected over a 5-year period (2011-2015). The average age of this patient population is 60.5 years and only one of the patients was female. $87.5 \%$ of the patients had no significant medical history and the remaining had a past medical history of ischemic heart disease. The same surgeon performed all repairs; using the Trans abdominal pre-peritoneal (TAPP) approach and a 3rd generation cephalosporin was used as prophylactic antibiotics in all cases. The average operating time was 95 minutes (longest duration being 120 minutes). All patients were discharged on the same day or on day one post-operative intervention. 
These cases were followed up prospectively to identify any recurrence of inguinal hernias or mesh infections. There were a total of fifty-nine (59) elective laparoscopic repairs from private institution A and twenty-two (22) elective repairs from private institution B. A variety of mesh was utilised, including materials such as polyester, polypropylene and composite mesh of polypropylene and polyglactic acid. All with their individual varying biochemical properties and of diverse brands.

Of the 59 elective repairs at institution A, six (6/59) presented with infection at the site of mesh placement (Figure 1). All infected mesh was removed laparoscopically at this institution (Figure 2) and there was one (1/59) case of recurrence of inguinal hernia. Of the 22 elective repairs at institution $B$, six $(6 / 22)$ presented with infection at the site of mesh placement. In all but one case, the mesh was removed laparoscopically and there was no recurrence present in any of these repairs.

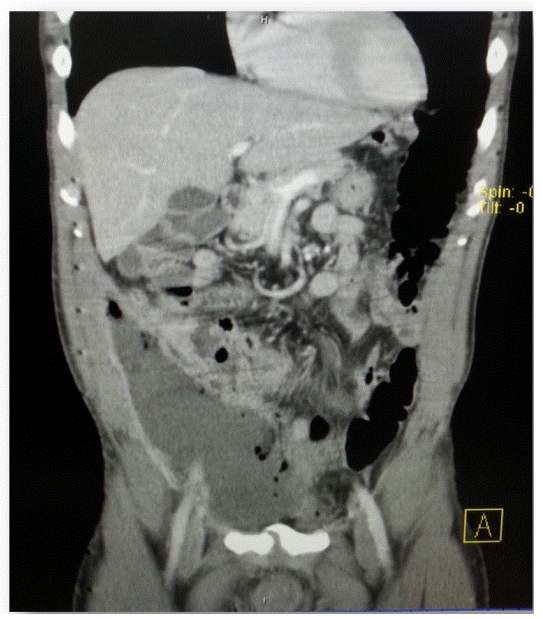

Figure 1: Coronal view of a CT scan of the abdomen and pelvis, showing a large fluid collection in the pre-peritoneal space over the right lower quadrant of the abdomen. This patient had a TAPP repair of a right inguinal hernia.

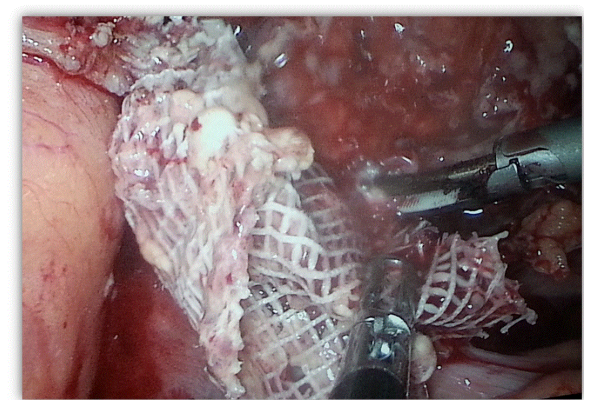

Figure 2: intra-operative photograph showing the infected polyester mesh during laparoscopic removal.

The patients presented with low-grade fever, as well as pain and swelling at the site of infection. The diagnosis of mesh infection was made by way of clinical examination, with the aid of laboratory and radiological investigation, including ultrasound and computed tomography. Once a clinical diagnosis of mesh infection was made, all patients were started on broad-spectrum oral antibiotics. Although the microbiology in the majority of the cases showed no bacterial growth, 2 cases grew gram negative bacillus-achromobacter species and 1 case grew pseudomonas aeruginosa.

In all twelve (12) cases of deep surgical site infection, the mesh consumed in these repairs was that of the polyester material. These cases presented with evidence of an infective process, within a variable time frame, ranging from four (4) months to twenty-nine (29) months. Laparoscopic removal was performed within close proximity of presentation.

\section{Discussion}

Mesh placement has become an integral part of inguinal herniorraphy, especially with the introduction of the Lichtenstein repair, and laparoscopic repairs-such as the TEP and the TAPP. The superiority and advantages of; compared to non-mesh options, have been demonstrated over the decades [6,7]. With an increase number of laparoscopic inguinal hernia repairs being performed, boasting shorter hospital stays, in addition to, quicker patient recovery and satisfaction; some dreaded complications have been noted as well. Mesh infection post laparoscopic inguinal hernia repair leads to the daunting management of removing the infected implant for successful patient management to be attained $[8,9]$.

The biological properties of mesh are widely varied-based on pore size, filament structure, weight, shrinkage and absorbability [10]. It should not be taken lightly; although done routinely, when a mesh implant is used in surgical practice - a foreign material is being introduced, with the goal of creating an inflammatory reaction [11]. Some factors have been proposed as an underlying or possible potentiator for the increase likelihood of mesh implant infection. These include the increase inflammatory reactions noted with poly-filament type meshes, and free unrestricted migration of bacterial organisms associated with micro porous mesh (size $<10 \mu \mathrm{m})$ [10,12]. It is also pivotal to mention that surgical technique, with thoughtful tissue handling, does play a critical role in surgical outcome [13].

Although recent studies show that the use of antibiotic prophylaxis has no additional benefit in preventing deep infections with mesh involvement when an endoscopic/laparoscopic technique is used to repair an inguinal hernia [14], we still used prophylactic antibiotics in all of our cases, and there was still a significant incidence of mesh infection in our population.

From as early as the 1950s, one of the initial mesh utilised is that of polypropylene mesh, with its non-absorbable mono-filamentous structure, and it is still widely and regularly used today. This prolene mesh is actually categorised as a heavy weight mesh $\left(100 \mathrm{~g} / \mathrm{m}^{2}\right)$, which has been associated with evidence of chronic inflammatory reactions in vivo [15]. As a result, over the years several advancements have been made in understanding not only the biological, but also the mechanical properties of mesh. This has led to the creation of several composite, light- weight mesh. Despite this, the ideal mesh is still yet to be discovered [12,16].

Polyethylene tetraphthelate (polyester) mesh is a multi-filament mesh. It was envisioned that its use would decrease bacterial adherence and, hence, cause less infections. However, others object to this, demonstrating the association of the increase surface area of multi- 
Citation: Bascombe N, Calderon C, Payne O, Bobb KA, Harnanan D, et al. (2017) Laparoscopic Inguinal Hernia Repair and Mesh Infection: Does the Type of Mesh Used Matter?. J Surg Anesth 1: 101.

Page 3 of 3

filament mesh leading to persistent bacterial ingrowth, and also, difficulty with removal of these adherent implants if infection does occur $[17,18]$. Along with the naysayers, other authors have shown comparably acceptable results with the use of polyester mesh [19].

We have since stopped using the polyester mesh, and to date, we have no reported cases of mesh infection.

\section{Conclusion}

The associated advantages of using mesh to repair inguinal hernias are numerous and it is a great asset in modern day surgery. The choice of the "right" mesh to use should depend on surgeon experience, personal outcome and of course, evidence-based.

\section{References}

1. Ger, R (1982) The management of certain abdominal herniae by intraabdominal closure of the neck of the sac. Preliminary communication. Ann R Coll Surg Engl 64: 342-344.

2. Wright D, Paterson C, Scott N, Hair A and O'Dwyer PJ, et al. (2002) Fiveyear follow-up of patients undergoing laparoscopic or open groin hernia repair: A randomized controlled trial. Ann Surg 235: 333-337.

3. Cawich SO, Mohanty SK, Bonadie KO (2013) Laparoscopic Inguinal Hernia Repair in a Developing Nation: Short-term Outcomes in 103 Consecutive Procedures. J Surg Tech Case Rep 5: 13-17.

4. Bhandarkar DS, Shankar M, Udwadia TE (2006) Laparoscopic surgery for inguinal hernia: Current status and controversies. J Minim Access Surg 2: 178-186.

5. Rehman S, Khan S, Pervaiz, APE (2012) Recurrence of inguinal herniae following removal of infected prosthetic meshes: a review of the literature. Hernia.16: 123-6.

6. Scott NW, McCormack K, Graham P, Go PM and Ross SJ, Grant AM, et al. (2002) Open mesh versus non-mesh for repair of femoral and inguinal hernia. Cochrane Database Syst Rev (4): CD002197.

7. Collaboration, EHT (2000) Laparoscopic compared with open methods of groin hernia repair: systematic review of randomized controlled trials. Br J Surg 87: 860-7.
8. Avtan L, Avci C, Bulut T, Fourtanier G, et al. (1997) Mesh infections after laparoscopic inguinal hernia repair. Surg Laparosc Endosc 7: 192-195.

9. Johanet H, Contival N, Coelio Club (2011) Mesh infection after inguinal hernia mesh repair. J Visc Surg 148: e392-394.

10. Brown CN, Finch JG (2010) Which mesh for hernia repair? Ann R Coll Surg Engl 92: 272-278.

11. Darouiche RO1 (2004) Treatment of infections associated with surgical implants. N Engl J Med 350: 1422-1429.

12. Bury K, Smietanski M, Justyna B (2014) Effects of macroporous monofilament mesh on infection in a contaminated field. Langenbeck's Arch Surg 399: 873-877.

13. Alfieri S, Di Miceli D, Doglietto GB (2005) Randomized clinical trial assessing impact of a lightweight or heavyweight mesh on chronic pain after inguinal hernia repair. Br J Surg 92: 166-170.

14. Kockerling F Bittner R, Jacob D, Schug-Pass C, Laurenz C, Adolf D, Keller $\mathrm{T}$ and Stechemesser, B, et al. (2015) Do we need antibiotic prophylaxis in endoscopic inguinal hernia repair? Results of the Herniamed Registry. Surg Endosc 29: 3741-3749.

15. Johannes C, Lauscher MD, Kamal, Yafaei MS, Heinz J, Buhr MD and Jörg P, Ritz M, et al. (2008) Total Extraperitoneal Hernioplasty: Does the Long-Term Clinical Course Depend on the Type of Mesh? J Laparoendosc Adv Surg Tech 18: 803-8.

16. Pott PP, Schwarz ML, Gundling R, Nowak K, Hohenberger P, et al. (2012) Mechanical properties of mesh materials used for hernia repair and soft tissue augmentation. PLoS One 7: e46978.

17. Klinge U, Junge K, Spellerberg B, Piroth C, Klosterhalfen BSV, et al. (2002) Do multifilament alloplastic meshes increase the infection rate? Analysis of the polymeric surface, the bacteria adherence, and the in vivo consequences in a rat model. J Biomed Mater Res 63: 765-71.

18. Hanna M, Dissanaike S (2015) Mesh ingrowth with concomitant bacterial infection resulting in inability to explant: a failure of mesh salvage. Hernia 19: 339-344.

19. Ramshaw B, Abiad F, Voeller G, Wilson R, Mason E, et al. (2003) Polyester (Parietex) mesh for total extraperitoneal laparoscopic inguinal hernia repair: Initial experience in the United States. Surg Endosc Other Interv Tech 17: 498-501. 